\title{
Use of the Internet of Things in the Business Environment to Smart Business
}

\author{
Martin Húdik $^{1}$, Gabriel Koman ${ }^{1}$, Jorma Jaakko Imppola ${ }^{2}$ and Josef Vodák ${ }^{1}$ \\ ${ }^{1}$ University of Žilina, Faculty of Management science and Informatics, Univerzitná 8215/1, Žilina, \\ Slovak Republic; Email: gabriel.koman@fri.uniza.sk, martin.hudik@fri.uniza.sk, \\ josef.vodak@fri.uniza.sk \\ ${ }^{2}$ Seinäjoki University of Applied Sciences, School of Business and Culture, Kampusranta 11, \\ Seinäjoki, Finland; Email: jorma.imppola@seamk.fi
}

\section{*Corresponding Author: Gabriel Koman}

\begin{abstract}
The article discusses the use of Internet of Things (hereinafter as IoT) solutions in the social and business environment to support managerial decision-making in Smart businesses. The paper key objective is to assess the rate of increasing technological advancement of the IoT which already affects us all, so it is not possible to talk about the IoT as a matter of the future. Currently, modern technologies provide specific level of digitization of business processes. Due to the penetration of information and communication technologies (hereinafter as ICT) in all areas of social life and business processes, it is possible to implement decisions on product production based on customer needs and requirements. This trend is mainly due to technological advances in ICT and the Internet. Thanks to the internet and the phenomenon called Internet of Things, it is possible to achieve higher profits and improve the quality of life in society. The manuscript main findings can be summarized through a statement that all the businesses try to implement the concept of IoT in their processes, and thus they become smart businesses. Thanks to IoT, businesses can quickly process data and distribute the results to responsible people for decision-making in the enterprise.
\end{abstract}

Keywords: Business, management, information technology, smart business, Internet of Things

\section{Introduction}

Internet of Things (IoT) can be seen as a part of the Internet of the future, which will combine billions of smart devices that will communicate with each other. The important idea of the internet of Things is a high impact on the aspects of everyday life and the behavior of potential users. The effects of the introduction of the Internet of Things will be visible from a private user point of view both in the professional and personal area. Similarly, from the perspective of business users, aspects of the Internet of Things will be important in areas such as automation, industrial manufacturing, 
and related logistics, process management, but also intelligent transport of people and goods or materials. The Internet of Things is meant to improve people's daily lives. The Internet of Things will make homes, offices and vehicles more intelligent and will probably collect useful data. Sensors could help us understand nature processes and pollution of the environment. Autonomous vehicles and smart cities could change the way in which public spaces are built and managed. However, many of these technological solutions would affect our privacy.

\section{Data and Methods}

In order to get the information necessary for the creation of conclusions in the field examined, an analysis of the documents focusing on the area of the Internet of things and the related case studies of the use of this technology in practice was carried out. The primary source of information was the internet and scientific research articles on the analyzed issue. The obtained data from the analysis were evaluated qualitatively. Other scientific methods that were used to obtain and assess the necessary information include $[1,2]$ :

- Synthesis, for the purposes of combining the findings and information into a complex whole.

- Comparison, for comparing the theoretical knowledge of authors in the framework of IoT, as well as for comparing the use cases of IoT technology.

- Deduction, for drafting recommendations for business managers to support future decisionmaking.

- Induction, for the formulation of recommendations for managers. Also, this method was chosen because it is possible to look for other things that have already been published concerning the decision making of managers in the company.

The "Internet of Things" (IoT) was first used in 1999 by a British technology pioneer Kevin Ashton to describe a system in which objects formed by sensors in the physical world could be connected to the Internet. Ashton created this term to illustrate the possibilities of using RFID tags. Tags were used in business supply chains and the goal was to count and track goods without the need for human intervention. The first Internet "device" - an IP toaster that turn on and off via the Internet - appeared at an Internet conference in 1990. Over the next few years, other "things" were controlled through internet, including a soda machine at Carnegie Mellon University in USA and a coffee pot in the room at the University of Cambridge in the UK (remained connected to the Internet until 2001). This beginning has helped research and development in the field of "intelligent networking" set the foundation for today's Internet of Things [1,3].

The Internet Architecture Council (IAB) defines that the term 'Internet of Things' denotes a trend where a large number of embedded devices use the communication services offered by 
Internet protocols. Many of these devices, often 'intelligent objects', are not immediately controlled by humans, but exist as components in buildings or vehicles, or are dispersed in the environment [1]. In the Oxford Dictionary the term 'Internet of Things' is defined as: 'objects with computing devices in them that are able to connect to each other and exchange data using the internet' $[2,4]$.

IEEE Communications Magazine links IoT back to cloud services. The Internet of Things is the framework in which all things have representation and presence on the Internet. More specifically, the Internet of Things focuses on offering new applications and services spanning the physical and virtual worlds in which computer-to-computer (M2M) communication is essential for interaction between things and applications in the cloud [1,5].

Different definitions of the Internet of Things do not necessarily agree - they rather emphasize other aspects of the Internet of Things phenomenon from different uses cases. The Internet of Things can be defined as a technology that connects both traditional and unconventional devices to help people and businesses make better decisions in their daily lives. The basic features of the Internet of Things include [4]:

- Connectivity of any device with the global ICT network.

- Services related to things such as privacy, semantic consistency, etc.

- Heterogeneity of IoT devices, i.e. different hardware platforms and networks.

- Dynamic changes of devices.

- Scalability of devices that communicate with each other and devices connected to the Internet.

- Security within the IoT network, such as securing personal data, endpoints and other data.

- The connectivity of devices to the network and their compatibility, i.e. the ability to produce data.

\section{Utilizing the Social-Business Environment}

Internet of Things, sensors and actuators, interconnected by networks with computer systems, has gained enormous attention in recent years. The McKinsey Global Institute has attempted to map how Internet of Things technology can create real economic value. Based on the results of this analysis, it can be assumed that IoT has a total potential economic impact of $\$ 3.9$ trillion to $\$ 11.1$ trillion per year by 2025 (see Table 1) [6]. 
Table 1 Estimated potential of the Internet of Things. Source: [6]

\begin{tabular}{cc}
\hline Application & $\begin{array}{c}\text { Scope in 2025 } \\
\text { (In trillions of USD) }\end{array}$ \\
\hline Factories & $1,2-3,7$ \\
\hline Cities & $0,9-1,7$ \\
\hline People & $0,2-1,6$ \\
\hline Retail & $0,4-1,2$ \\
\hline Outdoors & $0.6-0.9$ \\
\hline Workplaces & $0.2-0.9$ \\
\hline Vehicles & $0.2-0.7$ \\
\hline Homes & $0.2-0.3$ \\
\hline Offices & $0.1-0.2$ \\
\hline
\end{tabular}

\subsection{Internet of Things in the Business Environment}

IoT devices record and transmit data to monitor critical processes, deliver new insights, increase efficiency and enable companies to make more informed decisions. Organizations do not need to rely on predictions, they can know what is truly happening. There are several key factors that can be used by IoT in a business to support digital transformation [7]:

- Gaining business information and customer experience through connected devices across industries to gain greater insight into business operations and how customers use their products or services.

- Reduce costs and downtime, using tablets, AR headphones or smart goggles and other interconnected devices, to get up-to-date information on process flow in factories or other industrial facilities.

- Achieve efficiency and increase productivity of key business processes by connecting them

- Asset tracking and waste reduction, based on process flow and material consumption data in real or near real time.

- Creating new business models thanks to quickly available information about meeting/not meeting customer needs and requirements.

IoT also enables organizations to move away from conventional business models to new sources of income. The data obtained is often of value in itself, allowing customers to be offered services based on the nature of the interconnection of products and often offset the initial cost of entry. 


\subsection{Internet of Things in a Social Environment}

The use of IoT technology in a business environment is less and less different from that of ordinary people. The main areas of IoT use by mainstream users (people) are [6]:

- Healthcare - an intelligent hospital based on rapid and automatic resource allocation according to specific patient requirements.

- Smart city - a smart company based on links within innovative IoT concepts in a specific location.

- Public sector - traffic management with D2D solutions in road traffic with advanced integration of diverse infrastructure and services.

- Sport - IoT of sport based on facilitating interactions between athletes, sporting objects, team, health and followers.

\subsection{Taiwan YouBike - Case Study}

Taiwan's YouBike is a public bicycle system that allows people to rent bikes for a short period of time with their first 30 minutes for free. It operates in four different cities, with more than 700 stations. Each bike is equipped with RFID sensors and IoT devices at docking stations, terminals and gateway terminals. Sensors help YouBike monitor the status of its fleet. IoT solution and technology provided by Intel, Advantech and Microprogram helped the company $[8,9]$ :

- to ensure a rapid increase in customer service from 150,000 users to over 3.3 million,

- the ability to process more than 100,000 transactions per day.

All these data are transferred to cloud servers for analysis, allowing management to maintain stable service operation.

\subsection{Weka Intelligent Refrigerator - Case Study}

According to the World Health Organization, approximately 1.5 million children worldwide die from vaccinated diseases every year. Part of the problem is that many vaccines require constant cooling, and this is not always possible in regions with unreliable power supply sources.

Thanks to IoT implementations from Weka, it was possible to develop an intelligent vaccine refrigerator that is small enough to fit into a delivery truck. The refrigerator ensures a constant temperature and automates the storage, monitoring and delivery of vaccines. It can provide proactive alerts when temperatures start to fluctuate. Cloud-based big data analysis helps healthcare providers deliver the right amount of vaccines to the right clinics [9]. 


\subsection{Tyréns AB Smart Building - Case Study}

Tyréns AB, based in Sweden, is a consulting firm that, among other projects, helps create better, safer and more sustainable buildings and communities. The IoT solution was implemented by IBM, Intel, Yanzi and SVSi. Within the project, 1,000 sensors were installed to record various data on buildings (eg temperatures, accesses, movement of people, etc.). The aim of the project was to understand the use of buildings and to streamline the resources spent on their operation. By analyzing the collected data, it was possible to streamline building management, apply the retrieved information to support custom processes, and share data with clients [9].

\subsection{Cornelius Smart Vending Machines - Case Study}

The company produces vending machines for beer, must, juices, teas, frozen drinks and other beverages. The company created a need to collect and analyze data from its machines, for the needs of transformation of operations and processes in the internal and external environment of the company. With the support of Trek10 developers, the company has built a new IoT system that uses Amazon Web Services offerings such as AWS IoT, Lambda and Kinesis Firehouse. Thanks to the implementation of IoT solution, the company can [9]:

- proactively manage and identify support services for customers before accepting their demands,

- retrieve and analyze data throughout the supply chain

- to apply the information obtained from marketing activities,

- benefits implementation solutions IoT in the company's also significantly reduce back-end IT infrastructure costs (a few dollars per machine per year).

\subsection{GTX Shoes - Case Study}

This product was developed using IoT technology from Telefónica and was designed for people with dementia, autism, cognitive impairment or other similar disabilities. Smart Shoes automatically transmits carrier location data, enabling caregivers and relatives to quickly and easily locate their loved ones by accessing a web portal or smartphone application. IoT devices are in the shoes, no one sees it, and the patient does not need to remember to put on something specific [9].

\section{Results}

The Internet of things is now dynamically evolving. Its development supports several trends, such as research and development, Moor law, cloud computing and significant advances in data analysis. It is also interesting to quantify the potential of the internet of things. By 2025, the total potential 
economic impact of 3.9 trillion to USD 11.1 trillion per annum is projected. Despite the dynamism of development, IoT definitions are not settled. Their diversity is precisely emphasized by the different aspects of this phenomenon - technology [10].

The Internet of Things can be used not only in the business to save costs, better customer data gathering, increase productivity and efficiency, but also in everyday life. Smart cities are being built, traffic is being managed effectively. All the facts make people's life easier and also the quality of life is better [11-13].

It is important for business managers to have enough data or information to make the right decisions. Not only information, but also time is an important aspect in their decision-making. Internet of Things technology could make it easier for business managers to make decisions about products and their locations. Based on the information that the company receives from the sale of goods or services, managers can decide how to improve marketing of products that are not sold and see why they are not sold. On the contrary, what other requirements and needs customers have. Managers could streamline communication and collaboration with their co-workers, thereby increasing employees' motivation to work more responsibly, thus increasing the productivity of all employees in the company. The data helps organizations get to know their customers better. With this knowledge, organizations can begin to differentiate their marketing strategies and their offers to increase sales. A business can create targeted marketing [14,15].

Based on customer information, the company could improve the production of its products. Employees could analyze the available production resources better, faster and easier. An enterprise can also modify the supply chain and tailor it to obtain more accurate data from its partners. Managers who make logistics decisions could benefit from helped of the Internet of Things technology. Performance monitoring sensors are usually present in goods vehicles. The manager's task is to acquire, process and store sensor data. Later, it should analyze them to avoid wasting resources (e.g. fuel, finance, time) needed for transportation, it could also find ways to design more efficient delivery routes, or ensure preventive maintenance of vehicles. The manager's decision could also be the admission of qualified analysis to the company [16-18].

\section{Conclusion}

Internet of Things offers opportunities for improving the quality of life for both consumers and businesses. It helps to provide the right information to the right people so they can make better decisions. Decisions in the company can ensure better use of assets, lower operating costs, but also increase the satisfaction of employees and managers. Managers can assess risks in real time, ensuring stress relief. Globalization is increasing competition in the market, increasing the 
differentiation of products and services. Managers need to track competitive products where IoT also plays a role. IoT allows you to create new platforms - new business models.

\section{Acknowledgment}

This publication was realized with support of the Operational Program Research and Innovation in frame of the project: ICT for smart society, code ITMS2014 +: 313011T462, co-financed by the European Regional Development Fund.

\section{References}

[1] Eldridge, S., Chapin, L. \& Rose, K. (2015). The Internet of Things: An Overview. Retrieved September 20, 2019, from https://www.internetsociety.org/resources/doc/2015/iot-overview.

[2] Falát, L. \& Holubčík, M. (2017). The influence of marketing communication on financial situation of the company - a case from automobile industry. Procedia Engineering. 192, 148153.

[3] Internet of things. (2019). Retrieved September 29, 2019, from https://en.oxforddictionaries.com/definition/internet_of_things.

[4] Soviar, J., Holubčík, M., Rechtorík, M. \& Pollak, F. (2019). The Presentation of Automotive Brands in the On-Line Environment The Perspective of KIA, Peugeot, Toyota and VW in the Slovak Republic. Sustainability. 11(7), 2132.

[5] Holubčík, M. \& Falát, L. (2016). Possible implementations of prediction models for forming global cooperation relations. In Globalization and its socio-economic consequences - 16th international scientific conference, (pp. 670-677). Rajecke Teplice, Sovak Republic.

[6] Patel, K.K., Patel, S.M., Salazar, C. \& Scholar, P.G. (2016). Internet of Things-IOT: Definition, Characteristics, Architecture, Enabling Technologies, Application \& Future Challenges. International Journal of Engineering Science and Computing. 6(5), 6122-6131.

[7] Aharon, D., Bisson, P., Bughin, J., Dobbs, R., Chui, M., Manyika, J. \& Woetzel, J. (2015). Unlocking the potential of the Internet of Things. Retrieved October 19, 2019, from https://www.mckinsey.com/business-functions/digital-mckinsey/our-insights/the-internet-ofthings-the-value-of-digitizing-the-physical-world.

[8] Hobbs, A. (2018). Five ways the Internet of Things is transforming businesses today. Retrieved October 20, 2019, from https://internetofbusiness.com/5-ways-the-internet-ofthings-is-transforming-businesses-today/. 
[9] Harvey, C. (2018). Top IoT Projects: 8 Case Studies. Retrieved October 22, 2019, from https://www.datamation.com/networks/slideshows/top-iot-projects-8-case-studies.html.

[10] Ray, P.P. (2018). A survey on Internet of Things architectures. Journal of King Saud University - Computer and Information Sciences 30, 291-319.

[11] Hasan, H., AlHadhrami, E., AlDhaheri, A., Salah, K. \& Jayaraman, R. (2019). Smart contractbased approach for efficient shipment management. Computers and Industrial Engineering. 136, 149-159. DOI: 10.1016/j.cie.2019.07.022.

[12] Oh, A.S. (2019). Designing smart supplier chain management model under big data and internet of things environment. International Journal of Recent Technology and Engineering. 8(2 Special Issue 6), 290-294. DOI: 10.35940/ijrte.B1055.0782S619.

[13] D'Aloia, M., Longo, A., De Carlo, F., De Leonardis, P., Rizzi, P. \& Rizzi, M. (2018). Project IAAP: An overview on optimizing business process in smart enterprises. In 110th AEIT International Annual Conference - AEIT 2018. 3-5 October 2018 (Code 143727) Bari, Italy. DOI: 10.23919/AEIT.2018.8577389.

[14] Anandhi, S., Anitha, R. \& Sureshkumar, V. (2019). IoT enabled RFID authentication and secure object tracking system for smart logistics. Wireless Personal Communications. 104(2), 543-560. DOI: 10.1007/s11277-018-6033-6.

[15] Fanti, M.P., Iacobellis, G., Mangini, A. M., Precchiazzi, I. \& Ukovich, W. (2017). A flexible platform for intermodal transportation and integrated logistics. In IEEE International Conference on Service Operations and Logistics, and Informatics - SOLI 2017. 18-20 September 2017 (pp. 224-229). Bari, Italy. DOI: 10.1109/SOLI.2017.8120998.

[16] Jabbar, S., Khan, M., Silva, B.N. \& Han, K. (2018). A REST-based industrial web of things' framework for smart warehousing. Journal of Supercomputing. 74(9), 4419-4433. DOI: 10.1007/s11227-016-1937-y.

[17] Cho, S. \& Kim, J. (2017). Smart logistics model on internet of things environment. Advanced Science Letters. 23(3), 1599-1602. DOI: 10.1166/asl.2017.8604.

[18] Guangyao, L., Xinzhong, F., Yunjia, D. \& Shuqiong, X. (2018). Pipelined soft packaging cargoes handling robot. MATEC Web of Conferences 175; In International Forum on Construction, Aviation and Environmental Engineering-Internet of Things - IFCAE-IOT 2018. 11-13 May 2018 (Code 141840). Guangzhou, China. DOI: 10.1051/matecconf/201817502028. 